\title{
La administración de servicios de salud: ¿debe el médico saber administrar?
}

\author{
Octavio Sierra-Martínez* \\ Hospital General «Dr. Manuel Gea González», Ciudad de México, México
}

«Podemos ver y comprobar fácilmente el derroche de las cosas materiales. Pero los movimientos torpes, ineficientes o mal dirigidos de los hombres no dejan nada visible o tangible detrás de ellos...»

Los principios de la administración científica (1911), Frederick Winslow Taylor

La administración se ha descrito como la separación de responsabilidades o del trabajo para que cada persona haga una tarea específica en menos tiempo y con mejores resultados, lográndose mejores destrezas en la persona.

La administración es una rama de las ciencias sociales que permite al ser humano hacer un uso eficiente de los recursos, tanto en forma individual como grupal; individualmente debemos administrar nuestros alimentos, el tiempo, la capacidad física, los recursos económicos, etc., lo que nos permite alcanzar mejores condiciones de vida.

Cuando hablamos de empresas, la administración permite organizar los recursos tanto humanos como materiales y físicos comprometiendo a cada uno de sus miembros a alcanzar mayores logros y cumplir con los objetivos para alcanzar las metas de la institución con éxito.
En el caso del médico, la especialización y sus actividades técnicas lo han alejado de la administración; por ejemplo, un médico se especializa en cirugía, posteriormente en gastroenterología, después en endoscopia hasta llegar a ser altamente especializado en endoscopia del páncreas.

Cuando una persona en forma individual no administra bien su tiempo o sus recursos no alcanza los objetivos trazados; por ejemplo, no termina una carrera, no logra una victoria deportiva o arrastra deudas crediticias; del mismo modo, una empresa con dispendio de recursos y pérdidas no calculadas puede llegar a la quiebra.

Dentro de los servicios médicos se han realizado cambios para mejorar la calidad y calidez de la atención médica que han obligado al médico clínico de todos los niveles (internos de pregrado, residentes y adscritos) a poner más atención en el expediente clínico, describir los diagnósticos en forma precisa (con base en la Clasificación Internacional de Enfermedades [CIE]-10) y conseguir mayor eficiencia de los procesos de atención médica, tanto en la consulta externa como en hospitalización, urgencias y procedimientos quirúrgicos; todo ello permite una mayor profesionalización y

\section{Correspondence:}

*Octavio Sierra-Martínez

Hospital General «Dr. Manuel Gea González»

Calzada de Tlalpan, 4800

Col. Belisario Domínguez Sección 16, Del. Tlalpan

C.P. 14080, Ciudad de México, México

E-mail: osierramartinez@gmail.com

Received for publication: 21-01-2018

Accepted for publication: 16-03-2018

DOI:10.24875/HMCM.M18000001 
menos demandas por errores médicos, y para ello se requiere de mayores controles de la eficiencia y eficacia del trabajo médico.

Por otro lado, el médico en las instituciones públicas ha puesto poca atención a cuestiones relacionadas con la administración de los recursos para la atención médica, y en la mayoría de los casos desconoce el costo de la hospitalización, de los procedimientos quirúrgicos, de los medicamentos, de los estudios de laboratorio o del desgaste de los equipos, pues considera que eso le corresponde al «personal administrativo», como único responsable, sin tomar en cuenta que con su trabajo diario el médico produce todos esos gastos.

Esta falta de conocimiento de los costos que implica la atención médica provoca el dispendio de materiales de consumo y el abuso de estudios de laboratorio o gabinete, y frecuentemente desemboca en escasez al superar los cálculos programados. Otro problema es el abuso en el uso de equipos, ya sea por desconocimiento de los manuales de operación o por un uso desmedido, que reiteradamente produce la sobrecarga de equipos y su desgaste prematuro.

Además entre el personal operativo hay poco conocimiento del proceso de adquisición de los insumos y equipos, de lo que significa e implica una licitación pública o una adjudicación directa. Por otro lado, habitualmente hay un desconocimiento de las metas e indicadores de su área de trabajo, considerando que su responsabilidad es sólo dar consulta, realizar cirugías o procedimientos técnicos propios de su especialidad.

Existen múltiples publicaciones dirigidas al público en general para aprender a administrar el tiempo y, por otro lado, miles de publicaciones y cursos para orientar y capacitar a quien dirige en la administración del servicio clínico, a la jefa de enfermeras, al administrador de servicios paramédicos ${ }^{1}$; sin embargo, es muy escasa la enseñanza de la administración en la carrera de Medicina. Revisando el currículo de diversas facultades y escuelas de medicina, es escasa o nula la presencia de materias relacionadas con la administración de servicios de salud ${ }^{2}$. Considero que en los tiempos en que vivimos, independientemente de la situación económica de nuestros hospitales, estados o países, se debería enseñar administración a los estudiantes de medicina, lo que mejoraría el funcionamiento de la institución.

Toda organización pública es una empresa pública y debe tener objetivos y metas establecidos en todos sus niveles, que deben cumplirse con economía y eficiencia.

Considero que debemos desarrollar una visión de conjunto de sistemas en la que participen todos los integrantes del equipo que brinda la atención médica.

Los jefes y directivos debemos transmitir a todo el equipo la situación financiera que se está viviendo en la institución: presupuestos, recortes, metas, indicadores de gestión y el costo de la atención individualizada de un paciente en las diferentes áreas del hospital (quirófano, terapia intensiva, hospitalización, etc.), así como los costos de los medicamentos y demás insumos.

El crecimiento y la eficiencia de una institución pública de salud dependen de la optimización de los recursos financieros, económicos y humanos, lo que sólo se consigue con el conocimiento y la colaboración de todo el equipo.

La pregunta que surge de todo esto sería: ¿el médico sería más consciente de que no debe desperdiciar recursos si conociera el presupuesto, cómo se distribuye, cuánto se destina a recursos humanos y cuánto a las metas de la institución, la atención médica, la enseñanza y la investigación?

La intención de esta nota no es refrendar la importancia de que las personas con responsabilidades de jefatura de departamento o división, o subdirección, deben tener una preparación en administración, ya que eso es una condición obligada, sino despertar la importancia de que todo el personal médico y paramédico esté informado de las condiciones en las que se trabaja en una institución pública, a sabiendas de que es responsabilidad de todos conocer los recursos con los que cuenta la institución, la ruta crítica del gasto, la importancia del ahorro, no sólo de insumos, 
sino también de energía, del mantenimiento, del cuidado de los equipos, lo cual seguramente redundará en un ahorro para la institución y a mediano plazo mostrará el cumplimiento de las metas e indicadores de gestión, lo que beneficiará a los pacientes, y aumentará el prestigio de la institución en función no sólo de la gran capacidad técnica de sus médicos, sino también de la organización y administración de los recursos.

Considero que todos los directivos de instituciones públicas y privadas de salud, incluyendo los hospitales de alta especialidad, tenemos el compromiso de informar a la comunidad médica y paramédica, lo que repercutirá en lo siguiente: disminuir el dispendio de estudios superfluos o excesivos, que en ocasiones no son revisados; utilizar más las bases de la clínica para ahorrar en estudios de imagen sofisticados, dejándolos sólo para casos de duda; hacer un análisis por pares de la especialidad que corresponda, ahorrando en materiales de consumo diario, evitando el desperdicio de suturas, gasas, vendas, medicamentos de consumo interno; $y$, del mismo modo, no abusar de los recursos humanos, especialmente de residentes e internos, para no provocar el síndrome de desgaste profesional (burnout), que genera el desgaste del individuo y un aumento del riesgo de errores médicos.

Considero que lograr difundir la importancia de la administración de los recursos en la atención médica permitirá hacer una medicina más responsable, no sólo desde el punto de vista de la atención misma, sino también del ahorro y eficiencia de los recursos económicos.

\section{BIBLIOGRAFÍA}

1. Pavón-León $P$, Gogeascoechea-Trejo MC. La importancia de la administración en salud. Revista Médica de la Universidad Veracruzana. 2004;4(1):13-6.

2. Universidad Panamericana. Licenciatura en Médico Cirujano. Plan de Estudios 2018. Facultad de Ciencias de la Salud. Número de Acuerdo SEP 962060. México DF.. [Internet] Disponible en: http://www.up.edu.mx/es/licenciatura/mex/medico-cirujano. 